Supporting Information for

\title{
Solid electrolyte interphase layers by using lithiophilic and electrochemically active ionic additives for lithium metal anodes
}

\author{
Saehun Kim, ${ }^{\dagger, \#}$ Tae Kyung Lee, ${ }^{\not, \#}$ Sang Kyu Kwak,, ,* and Nam-Soon Choi, ,,$*$ \\ $\dagger$ Department of Chemical and Biomolecular Engineering, Korea Advanced Institute of \\ Science and Technology (KAIST), 291 Daehak-ro, Yuseong-gu, Dajeon, 34141, \\ Republic of Korea \\ ¥ Photovoltaics Research Department, Korea Institute of Energy Research (KIER), 152, \\ Gajeong-ro, Yuseong-gu, Daejeon 34129, Republic of Korea \\ $\S$ Department of Energy Engineering, School of Energy and Chemical Engineering, \\ Ulsan National Institute of Science and Technology (UNIST), 50 UNIST-gil, Ulsan 44919, \\ Republic of Korea
}

\section{Corresponding Author}

E-mail: skkwak@unist.ac.kr (S. K. Kwak),nschoi@kaist.ac.kr (N.-S. Choi) 


\section{Experimental Section}

\section{Electrolytes and electrodes}

The no additive electrolyte was fabricated by dissolving $2 \mathrm{M}$ lithium bis(fluorosulfonyl)imide (LiFSI; $\geq 99.7 \%$, Chunbo Fine Chemicals Co., Ltd.) in 1,2-dimethoxyethane (DME; $\geq 99.9 \%$, Sigma-Aldrich). Then, lithium difluoro(bisoxalato) phosphate (LiDFOP; 1 wt.\%, Chunbo Fine Chem Co., Ltd.), lithium nitrate $\left(\mathrm{LiNO}_{3} ; 3\right.$ wt.\%, Sigma-Aldrich), and silver nitrate $\left(\mathrm{AgNO}_{3}\right.$; 0.05 wt. $\%$, Sigma-Aldrich) or 0.05 wt. $\% \mathrm{AgNO}_{3}$ were added to the no additive electrolyte for evaluation. These electrolytes were formulated in a glove box filled with argon gas. To reduce the water content, $\mathrm{CaH}_{2}$ was introduced to the electrolytes and stirred for $30 \mathrm{~min}$, followed by filtration. $\mathrm{LiNi}_{0.84} \mathrm{Co}_{0.11} \mathrm{Mn}_{0.05} \mathrm{O}_{2}(\mathrm{NCM} 84)$ cathodes were fabricated by using a slurry consisting of $95 \mathrm{wt} . \%$ active material, $2.5 \mathrm{wt} \%$ poly(vinylidene fluoride) (PVDF) dissolved in anhydrous $N$-methyl-2-pyrrolidone (NMP; 99.5\%, Sigma-Aldrich), and 2.5 wt.\% Denka black as the conducting agent. The proportions of $\mathrm{Ni}, \mathrm{Co}$, and $\mathrm{Mn}$ in the NCM84 cathodes were $84 \%$, $11 \%$, and $5 \%$, respectively. After applying the slurry on the Al foil, the NCM84 cathodes were pressed by a coater and dried under vacuum for $10 \mathrm{~h}$ at $110^{\circ} \mathrm{C}$ prior to use. The mass loading and areal capacity of the NCM84 cathode were $15.1 \mathrm{mg} \mathrm{cm}^{-2}$ and $2.65 \mathrm{mAh} \mathrm{cm}^{-2}$, respectively.

\section{Electrochemical evaluations}

For long-term cyclability tests, 2032-coin type full cells with an NCM84 cathode, a PE separator (Asahi; porosity: 38\%, thickness: $16 \mu \mathrm{m}$ ), and a Li metal anode (Honjo, thickness: $40 \mu \mathrm{m})$ were assembled in a glove box. The $40 \mu \mathrm{m} \mathrm{Li|NCM84} \mathrm{full} \mathrm{cells} \mathrm{were} \mathrm{precycled} \mathrm{and}$ cycled from 3.0 to $4.2 \mathrm{~V}$ under a fixed current of $\mathrm{C} / 10\left(0.265 \mathrm{~mA} \mathrm{~cm}^{-2}\right)$ and $1 \mathrm{C}(2.65 \mathrm{~mA}$ $\mathrm{cm}^{-2}$ ) at $25^{\circ} \mathrm{C}$ using a battery cycler system (WonATech WBCS 3000). Nyquist plots of the 
Li|NCM84 full cells were obtained by AC impedance analysis using a VSP-300 instrument (BioLogic) over the frequency range of $0.01 \mathrm{~Hz}-1 \mathrm{MHz}$.

Before cycling at $1 \mathrm{C}$, three standard cycles were conducted at a fixed current of $\mathrm{C} / 2(1.325$ $\mathrm{mA} \mathrm{cm}{ }^{-2}$ ). Fast discharging performance of Li|NCM84 full cells were conducted at various discharging rates $(\mathrm{C} / 2,1 \mathrm{C}, 2 \mathrm{C}, 3 \mathrm{C}, 5 \mathrm{C}, 7 \mathrm{C}$, and $10 \mathrm{C})$ under constant charging rate at $\mathrm{C} / 2$. To examine the recovery performance, both charging and discharging rates were fixed at $\mathrm{C} / 2$ for the last three cycles. The fast-discharge cyclability of Li|NCM84 full cells was evaluated at a discharge rate of $10 \mathrm{C}$ under a constant charge rate of $\mathrm{C} / 2$.

In the experiments aimed at improving the energy density of Li metal batteries (LMBs), high charge cut-off voltage $\left(4.4 \mathrm{~V}\right.$ vs. $\left.\mathrm{Li} / \mathrm{Li}^{+}\right)$, high areal capacity $\mathrm{NCM} 84$ cathodes $\left(4 \mathrm{mAh} \mathrm{cm}{ }^{-2}\right)$, and ultra-thin Li metal anodes $(20 \mu \mathrm{m})$ were used. Electrochemical floating tests were performed in the fully charged states of Li|NCM84 full cells at $4.2 \mathrm{~V}$ under a fixed current of $\mathrm{C} / 10\left(0.265 \mathrm{~mA} \mathrm{~cm}^{-2}\right)$ after precycling. In the aforementioned cell assembly, the electrolyte amount per milliampere hour (E/C ratio) was $13.8 \mathrm{mg} \mathrm{mAh}^{-1}$.

\section{Characterizations}

The existence of an Ag-based inner solid electrolyte interphase (SEI) on the Li metal anodes during aging in Li|NCM84 full cells was analyzed by high-power X-ray diffraction (XRD; D/MAX2500V/PC, Rigaku) studies and time-of-flight secondary ion mass spectroscopy (TOFSIMS). TOF-SIMS analysis was conducted using a spectrometer (ION TOF, Germany) in a target area of $50 \mu \mathrm{m} \times 50 \mu \mathrm{m}$ at a dose density of $3.44 \times 10^{13}$ ions $\mathrm{cm}^{-2}$. Ion maps and depth profiles were obtained using a $25-\mathrm{keV} \mathrm{Bi}^{+}$ion source and a $0.5-\mathrm{keV} \mathrm{Cs}^{+}$ion source, respectively, and the chamber pressure was preserved below $4.0 \times 10^{-9}$ mbar. The surface characterizations of NCM84 cathodes and Li metal anodes were conducted by ex situ X-ray 
photoelectron spectroscopy (Thermo Fisher Scientific ESCALAB 250Xi System; XPS) after aging (before cycling) or precycling, and at various charged states $(3.7 \mathrm{~V}, 3.8 \mathrm{~V}, 3.9 \mathrm{~V}$ vs. $\mathrm{Li} / \mathrm{Li}^{+}$, and fully charged states; Li metal anodes). The XPS equipment was operated with Al$\mathrm{K} \alpha(\mathrm{h} v=1486.6 \mathrm{eV})$ radiation in a high-vacuum state. To verify the extent of intergranular cracking in the NCM84 cathodes after cycling with and without $\mathrm{AgNO}_{3}+\mathrm{LiDFOP}+\mathrm{LiNO}_{3}$, cross-sectional field-emission scanning electron microscopy (FE-SEM; JSM-6700F, JEOL) measurement was conducted after ion milling (IM4000, Hitachi High-Technologies). The amount of $\mathrm{Ni}$ and $\mathrm{Al}$ ions in the electrolyte in contact with fully charged NCM84 cathodes with no additive- and $\mathrm{AgNO}_{3}+\mathrm{LiDFOP}+\mathrm{LiNO}_{3}$-derived cathode-electrolyte interfaces (CEIs) for $3 \mathrm{~d}$ at $60{ }^{\circ} \mathrm{C}$ was measured by inductively coupled plasma-optical emission spectrometry (ICPOES, 700-ES). The anodic limits of the electrolytes were determined by linear sweep voltammetry (LSV) using a VSP-300 instrument (BioLogic) at a scan rate of $1 \mathrm{mV} \mathrm{s}^{-1}$. Al was used as the working electrode, and Li metal (thickness, $700 \mu \mathrm{m}$ ) was used as the counter and reference electrodes. The beneficial effect of the in situ multilayer SEI on the structural stability of the Li metal anodes was confirmed by the cross-sectional SEM images of the Li metal anodes in the Li|NCM84 full cells obtained after 1 and 30 cycles with and without $\mathrm{AgNO}_{3}+\mathrm{LiDFOP}$ $+\mathrm{LiNO}_{3}$. The cross-sectional morphological studies of deposited $\mathrm{Li}$ on $\mathrm{Cu}$ substrates with and without $\mathrm{AgNO}_{3}+\mathrm{LiDFOP}+\mathrm{LiNO}_{3}$ in a 2032-coin cell and $1 \mathrm{~T}$ spacer were verified by FESEM analysis. All the aforementioned samples and experiments were rinsed with DME after cell disassembly and prepared in a glove box. 


\section{Computational details}

To investigate the molecular orbitals (i.e., highest occupied molecular orbital (HOMO) and lowest unoccupied molecular orbital (LUMO)) and the adsorption energies, the density function theory (DFT) calculations were performed. For the calculations of molecular orbitals, Beck's three-parameter hybrid functional combined with Lee-Yang-Parr correlation (B3LYP) functional was used for the exchange-correlation energy ${ }^{1,2}$. For the calculations of adsorption energies of electrolyte/additive on the Li (100) surface, the generalized gradient approximation (GGA) with the Perdew-Burke-Ernzerhof (PBE) functional ${ }^{3}$ was used for the exchangecorrelation energy. Note that for the Li (100) surface, it is the most stable surface in the Li metal $^{4}$. In the calculations of adsorption energies, the orbital cutoff and the smearing value were set to $5.1 \AA$ and $0.005 \mathrm{Ha}$, respectively. The $4 \times 5 \times 1 k$-point was used with MonkhorstPack grid ${ }^{5}$. All DFT calculations were performed by using DMol3 program ${ }^{6,7}$. In all DFT calculations, spin-polarized calculations were employed and van der Waals correction was adopted by using the Tkatchenko-Scheffler method ${ }^{8}$. All relativistic core treatments and the double numerical plus polarization (DNP) version 4.4 basis set were used to describe the core electrons and the atomic orbital basis set, respectively. The convergence criteria for geometry optimization were $1.0 \times 10^{-5} \mathrm{Ha}$ for energy, $0.002 \mathrm{Ha} / \AA$ for force, and $0.005 \AA$ for displacement. The self-consistent field converged until the energy was less than $1.0 \times 10^{-6} \mathrm{Ha}$. The Mulliken charge analysis method ${ }^{9}, 10$ was used for the analysis of atomic charges of molecules. An implicit environment was adopted by using the conductor-like screening model (COSMO) method ${ }^{11}$ with a dielectric constant of $\operatorname{DME}\left(\text { i.e., } 7.2 \text { at } 25^{\circ} \mathrm{C}\right)^{12}$. 
a

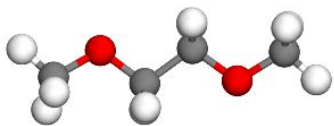

DME

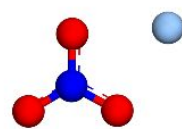

$\mathrm{AgNO}_{3}$

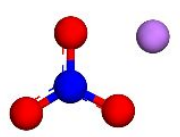

$\mathrm{LiNO}_{3}$

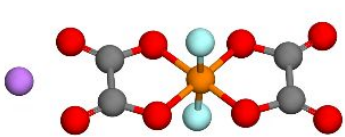

LiDFOP

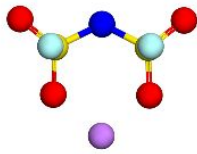

LiFSI

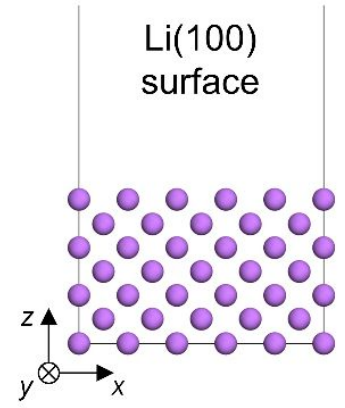

Oli OAg On OO

OC OF OS OP

b

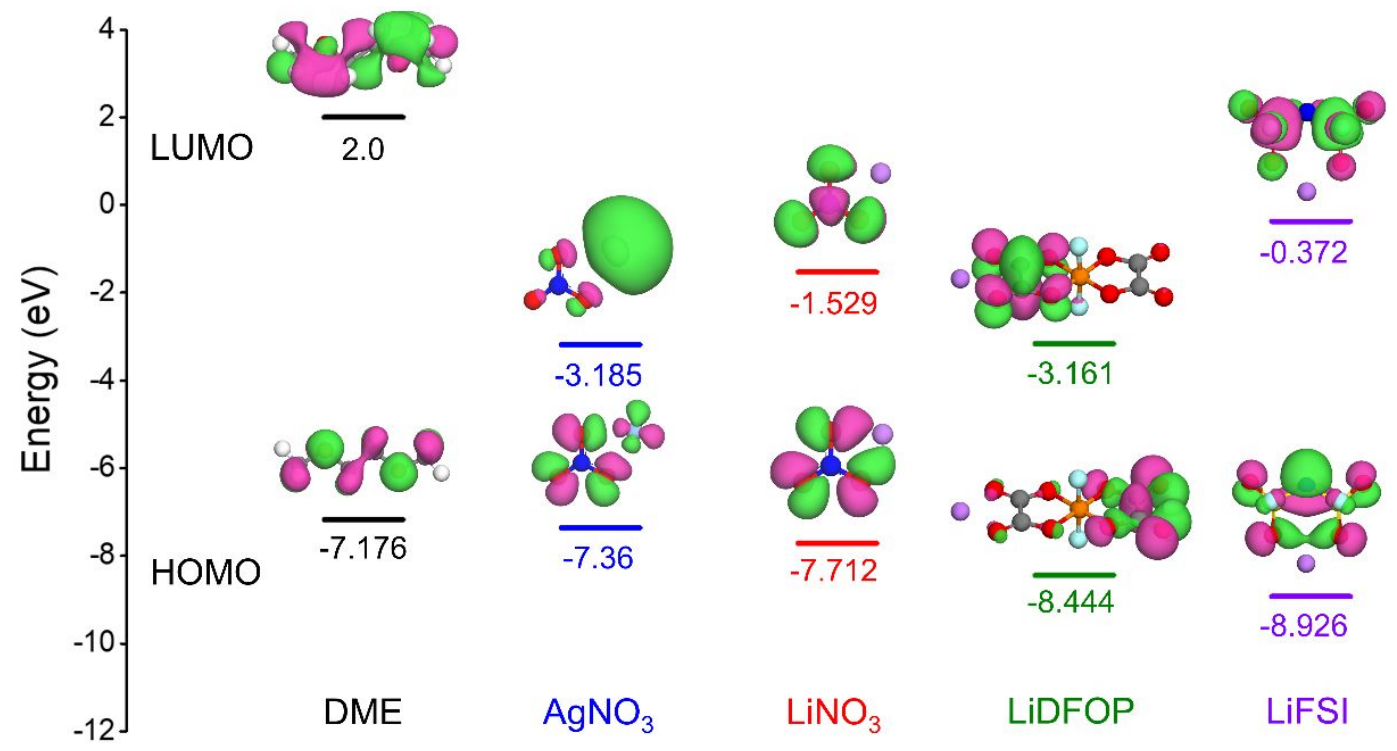

Figure S1. (a) Molecular structures of DME, $\mathrm{AgNO}_{3}, \mathrm{LiNO}_{3}, \mathrm{LiDFOP}$, and LiFSI and Li (100) surface structure. The Li metal surface is constructed by the $5 \times 4$ supercell of unit cell of Li surface along the $x$ - and $y$-axes. There are seven Li layers in the Li metal surface system and the bottom two layers are constrained. The vacuum spacing of Li metal surface system is over 20 Å. (b) HOMO and LUMO energy levels of DME, $\mathrm{AgNO}_{3}, \mathrm{LiNO}_{3}$, LiDFOP, and LiFSI. The isovalue of orbital is $0.03 e / \AA^{3}$. 

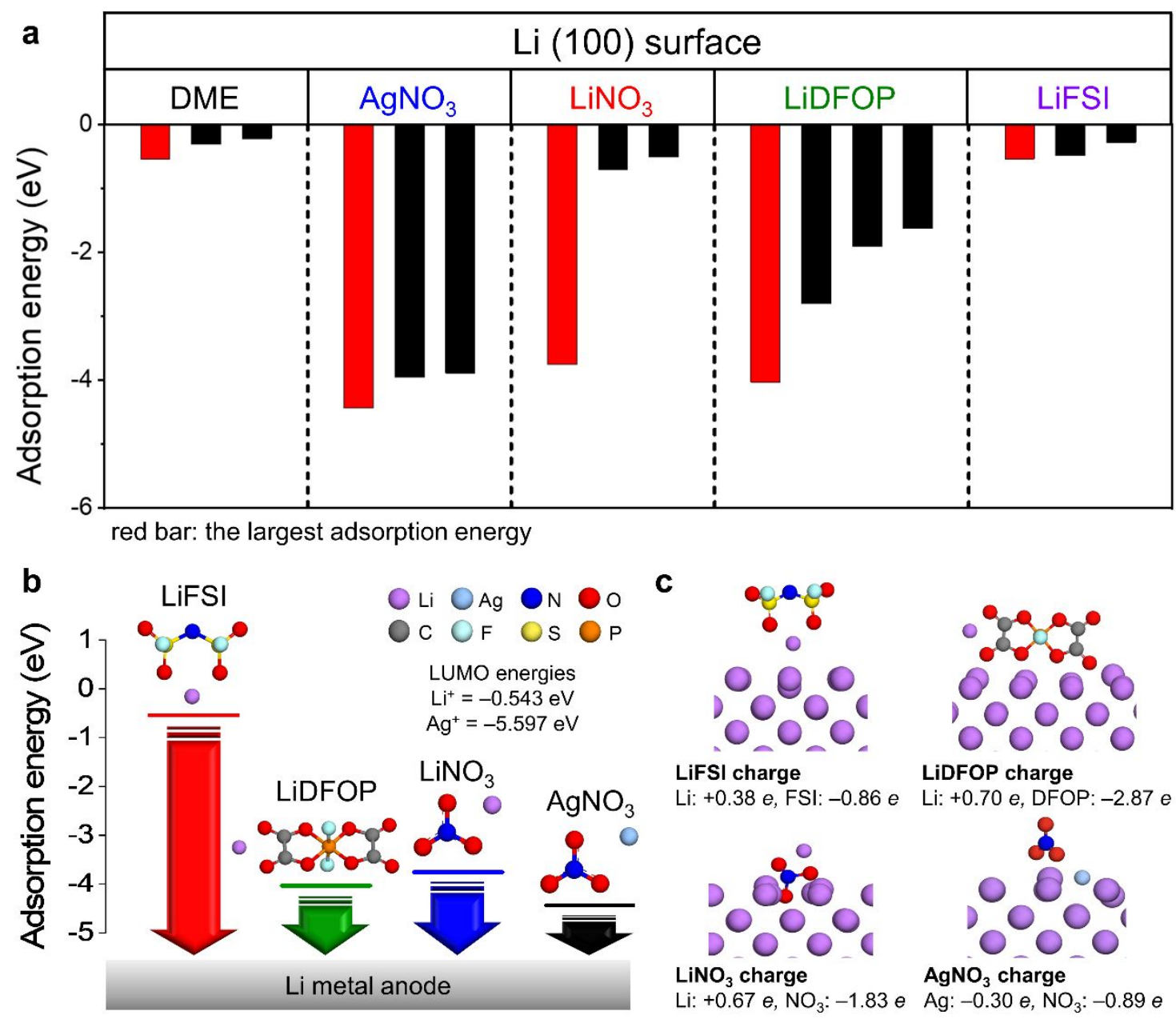

Figure S2. (a) Adsorption energies of DME, $\mathrm{AgNO}_{3}, \mathrm{LiNO}_{3}, \mathrm{LiDFOP}$, or LiFSI on Li (100) surface. Note that the red colored bars indicate the most strongly adsorbed cases (i.e., largest adsorption energies) in various configurations of each molecule on Li (100) surface. The black colored bars indicate other adsorbed cases. (b) Schematic illustration of adsorption energies of LiFSI, LiDFOP, $\mathrm{LiNO}_{3}$, and $\mathrm{AgNO}_{3}$ on the $\mathrm{Li}(100)$ surface. (c) Charge analyses of LiFSI, LiDFOP, $\mathrm{LiNO}_{3}$, or $\mathrm{AgNO}_{3}$ on $\mathrm{Li}(100)$ surface systems. 


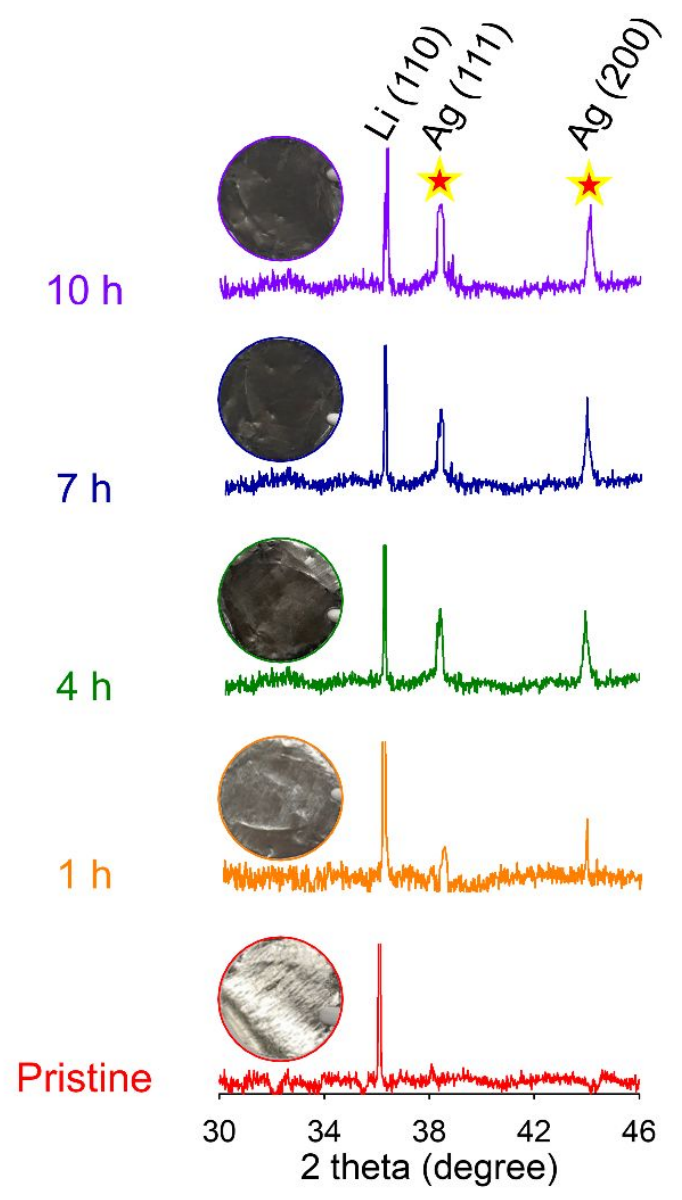

Figure S3. X-ray diffraction patterns of the Li metal anodes in Li|NCM84 full cells aged for 1, 4, 7, and $10 \mathrm{~h}$ with $\mathrm{AgNO}_{3}+\mathrm{LiDFOP}+\mathrm{LiNO}_{3}$. Inset: Digital photographs of the Li metal anodes retrieved from the Li|NCM84 full cells during aging. 


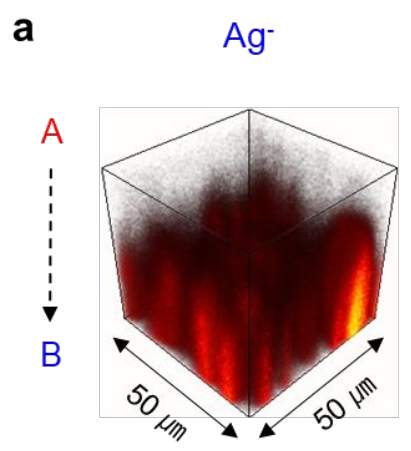

A : Outer SEI, B : Inner SEI

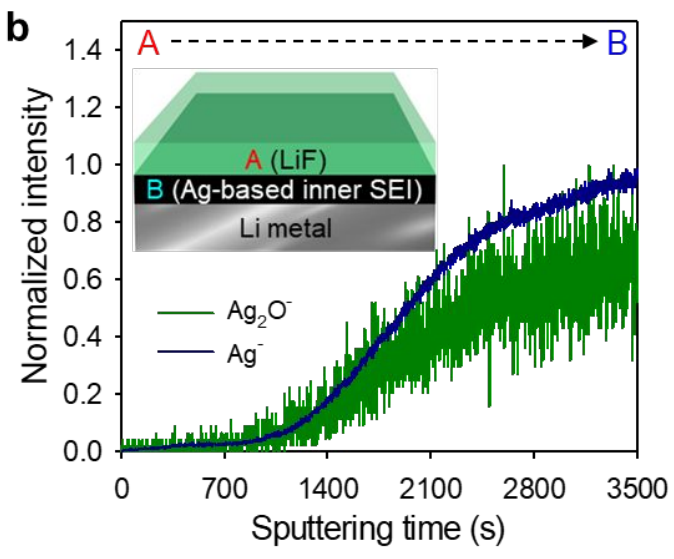

Figure S4. (a) $\mathrm{Ag}^{-}$3D TOF-SIMS image and (b) depth profile of the Li metal anode after aging for $10 \mathrm{~h}$ in $\mathrm{Li} \mid \mathrm{NCM} 84$ full cell with $\mathrm{AgNO}_{3}+\mathrm{LiDFOP}+\mathrm{LiNO}_{3}$. 


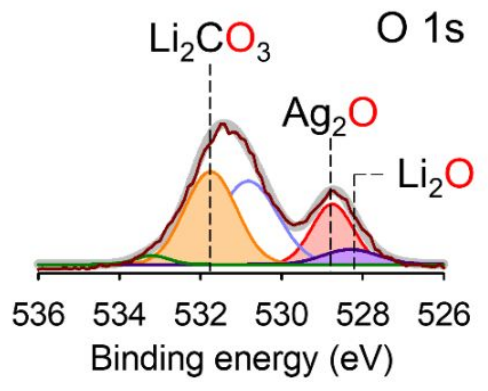

Figure S5. O 1s XPS spectra of Li metal anode retrieved from Li|NCM84 full cells after aging in $\mathrm{AgNO}_{3}+\mathrm{LiDFOP}+\mathrm{LiNO}_{3}$ electrolyte during $10 \mathrm{~h}$. 


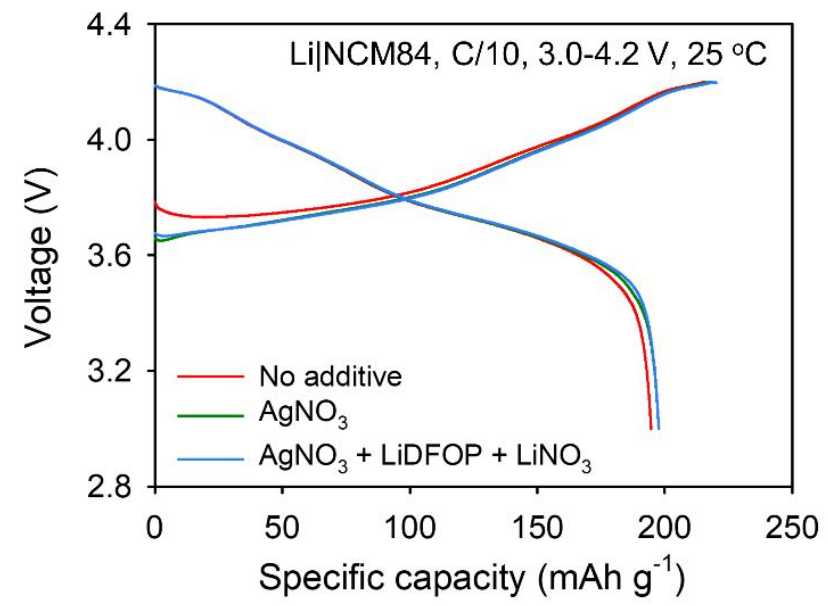

Figure S6. Voltage profiles of Li|NCM84 full cells with no additive, $\mathrm{AgNO}_{3}$, and $\mathrm{AgNO}_{3}+$ $\mathrm{LiDFOP}+\mathrm{LiNO}_{3}$ electrolytes during precycling. 


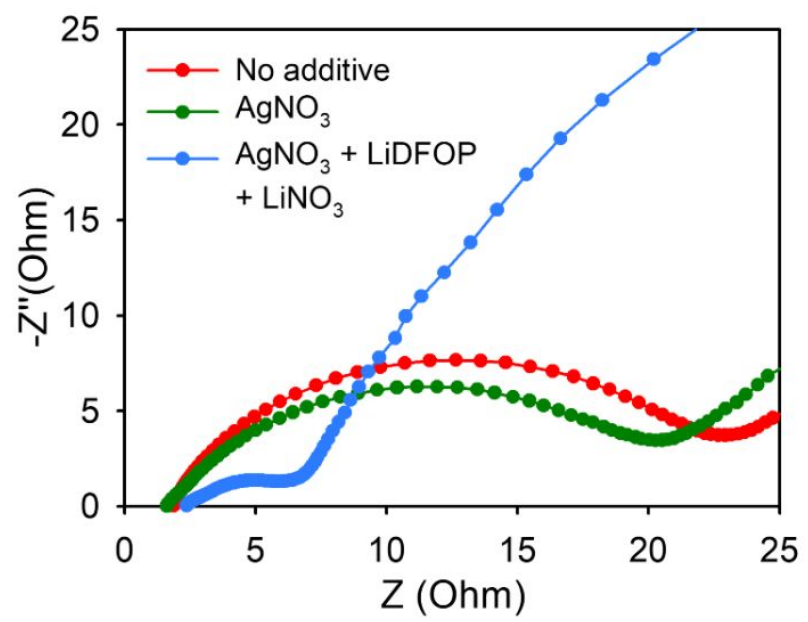

Figure S7. Electrochemical impedance spectra of Li|NCM84 full cells with no additive, $\mathrm{AgNO}_{3}$, and $\mathrm{AgNO}_{3}+\mathrm{LiDFOP}+\mathrm{LiNO}_{3}$ after precycling. 


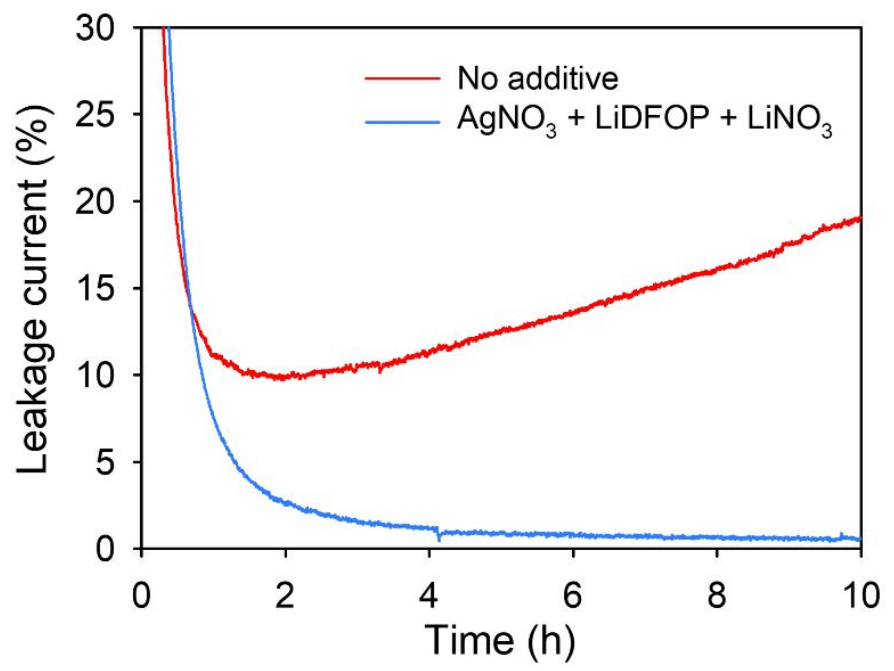

Figure S8. Result of the electrochemical floating test of Li|NCM84 full cells with and without $\mathrm{AgNO}_{3}+\mathrm{LiDFOP}+\mathrm{LiNO}_{3}$ at $4.2 \mathrm{~V}$ vs. $\mathrm{Li} / \mathrm{Li}^{+}$after precycling. 

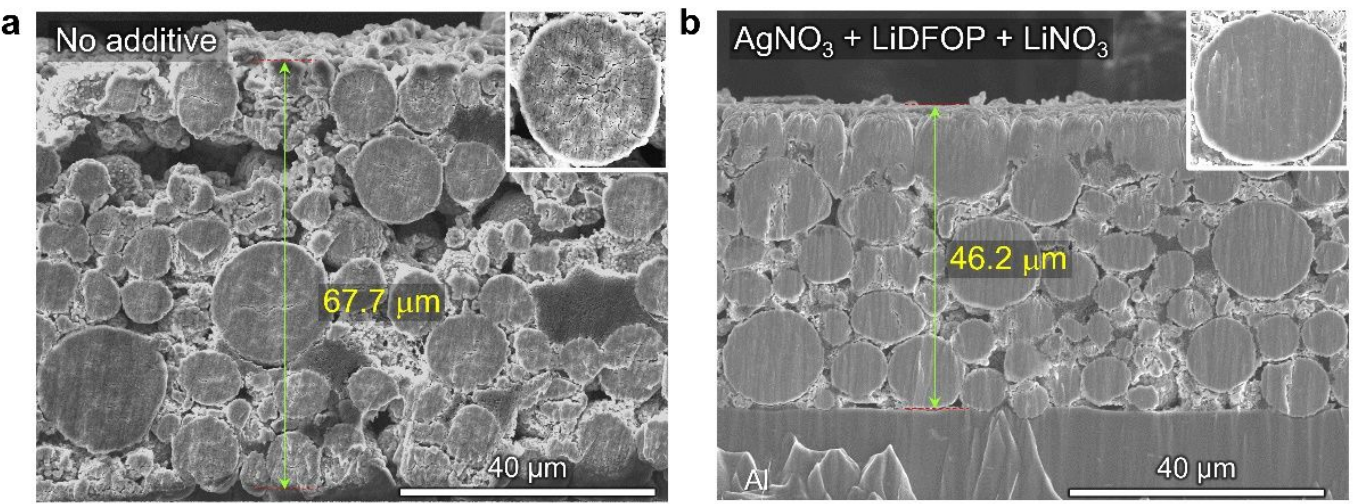

Figure S9. Cross-sectional SEM images of NCM84 cathodes after 60 cycles with and without $\mathrm{AgNO}_{3}+\mathrm{LiDFOP}+\mathrm{LiNO}_{3}$. The insets show the magnified NCM84 cathode particles. 


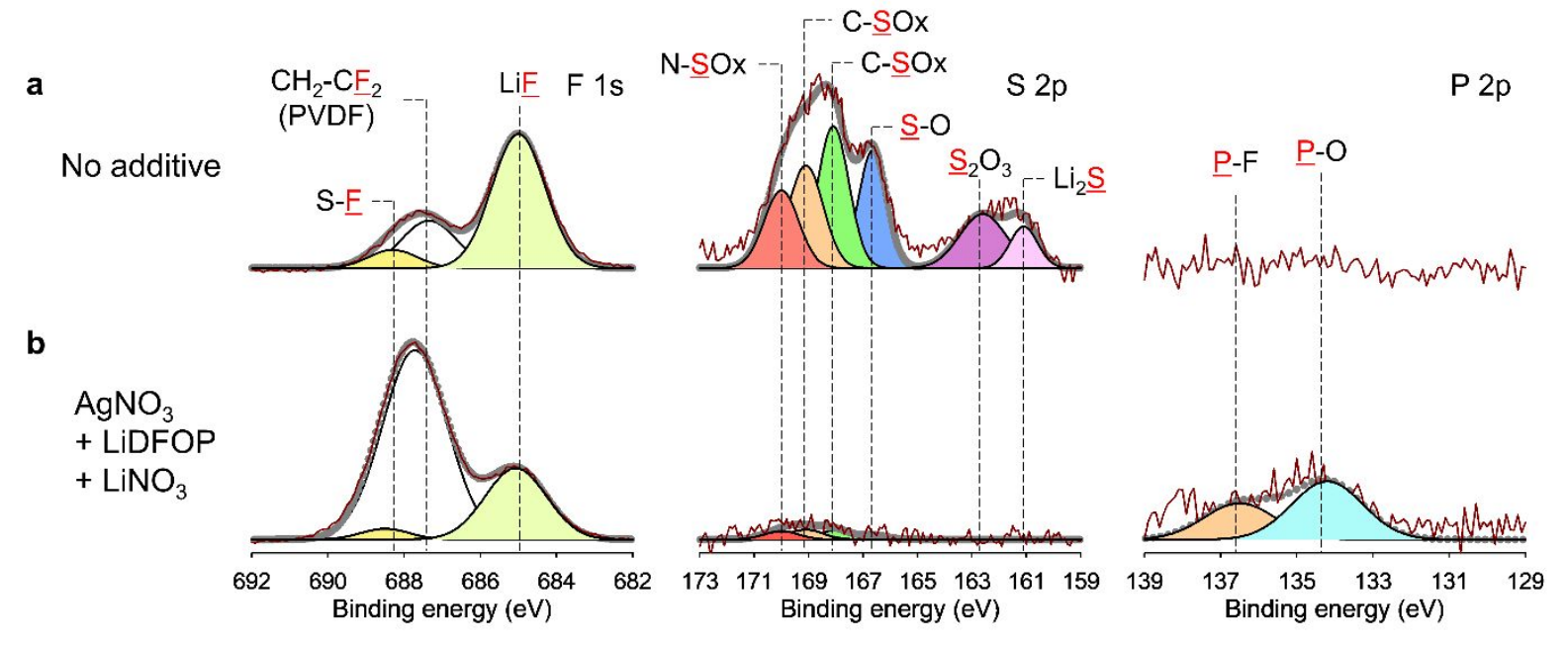

Figure S10. F 1s, S 2p, and P 2p XPS spectra of the NCM84 cathodes retrieved from $\mathrm{Li} \mid \mathrm{NCM} 84$ full cells precycled (a) without and (b) with $\mathrm{AgNO}_{3}+\mathrm{LiDFOP}+\mathrm{LiNO}_{3}$. 


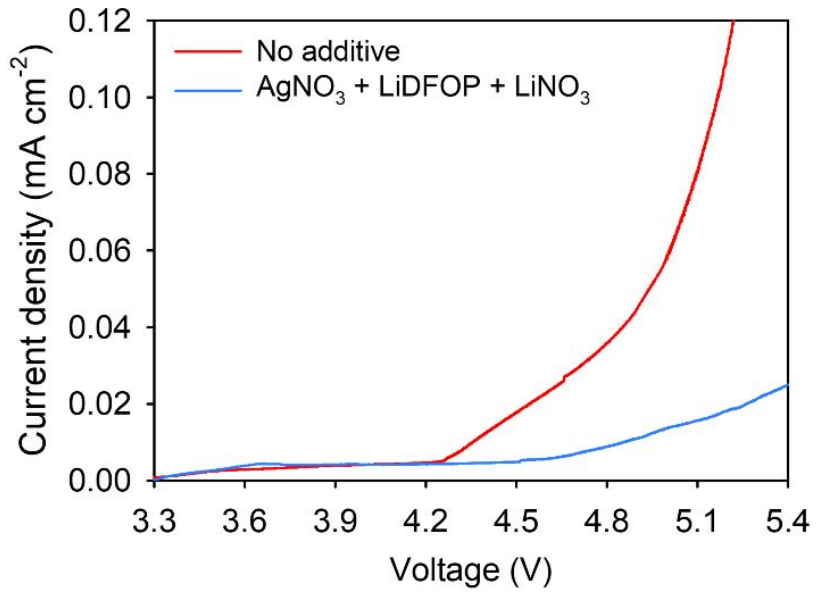

Figure S11. Linear sweep voltammetry curves of electrolytes with no additive and $\mathrm{AgNO}_{3}+$ $\mathrm{LiDFOP}+\mathrm{LiNO}_{3}$ at a scan rate of $1 \mathrm{mV} \mathrm{s}^{-1}$. Al served as the working electrode, and Li metal foil served as the counter and reference electrodes. 


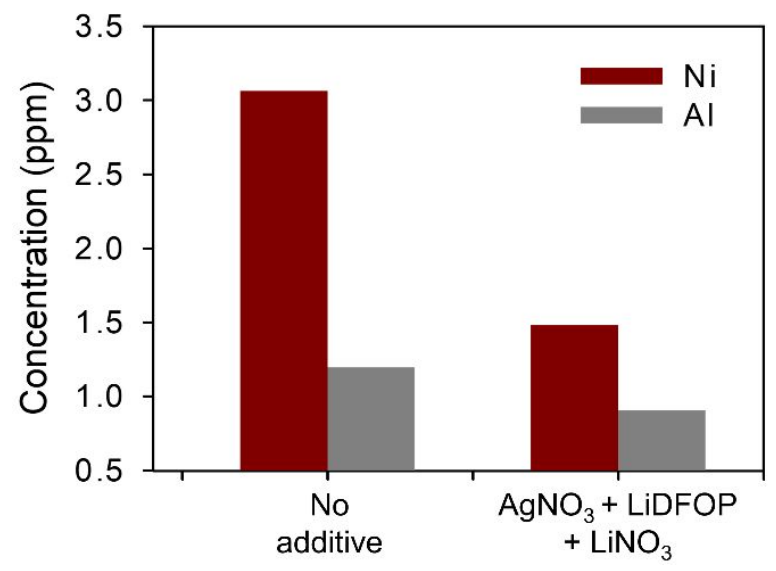

Figure S12. Concentration of dissolved $\mathrm{Ni}$ and $\mathrm{Al}$ ions detected in the no-additive electrolyte in contact with fully charged NCM84 cathodes with no additive- and $\mathrm{AgNO}_{3}+\mathrm{LiDFOP}+$ $\mathrm{LiNO}_{3}$-derived cathode-electrolyte interfaces for $3 \mathrm{~d}$ at $60{ }^{\circ} \mathrm{C}$. 

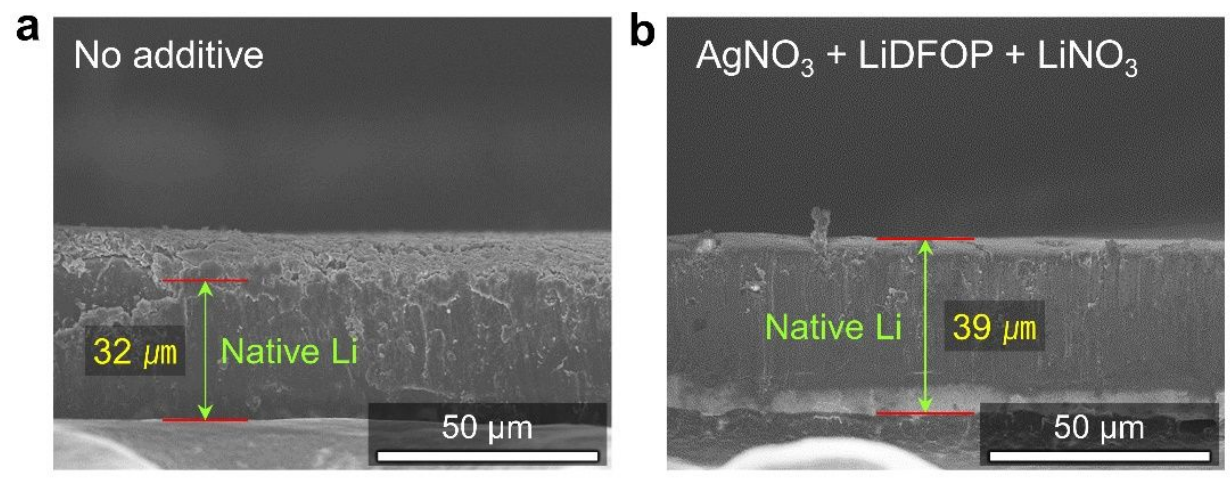

Figure S13. Cross-sectional SEM images of Li metal anodes after $1^{\text {st }}$ cycle in Li|NCM84 full cells with (b) no additive and (c) $\mathrm{AgNO}_{3}+\mathrm{LiDFOP}+\mathrm{LiNO}_{3}$ electrolytes. 

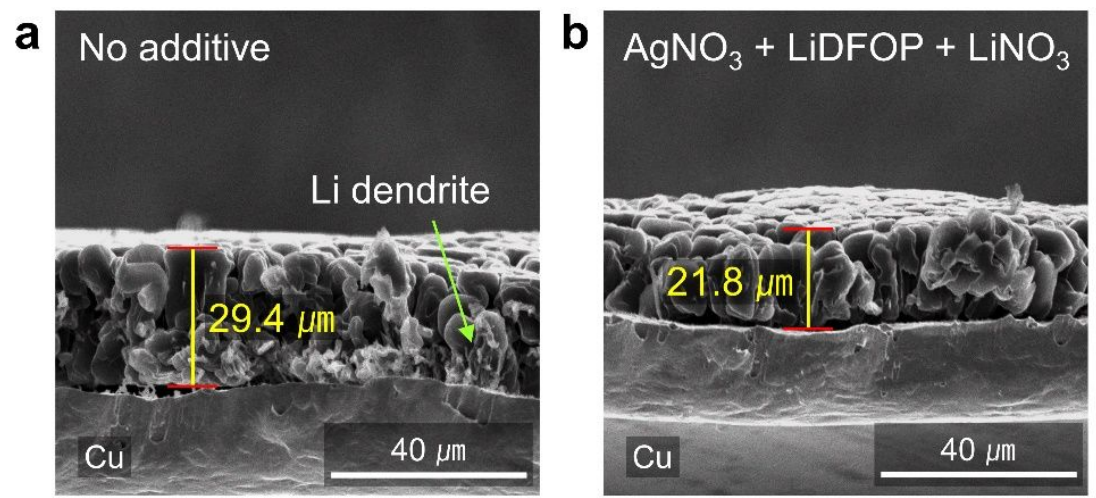

Figure S14. Cross-sectional morphology of Li deposited on $\mathrm{Cu}$ substrates (a) without and (b) with $\mathrm{AgNO}_{3}+\mathrm{LiDFOP}+\mathrm{LiNO}_{3}$. 

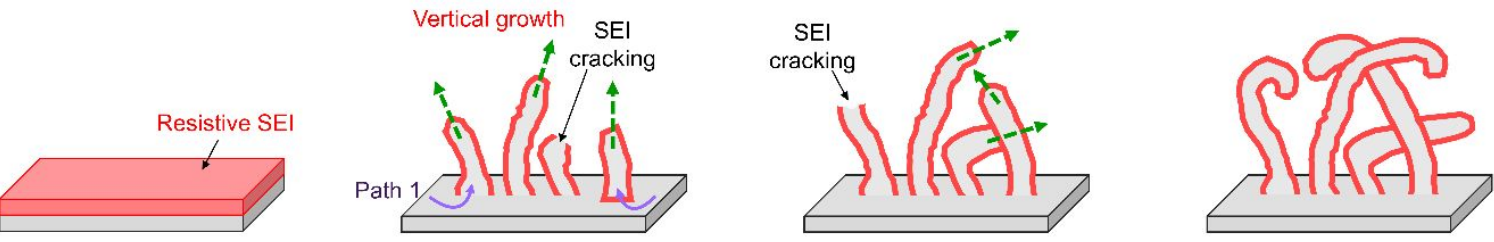

b

Lateral growth
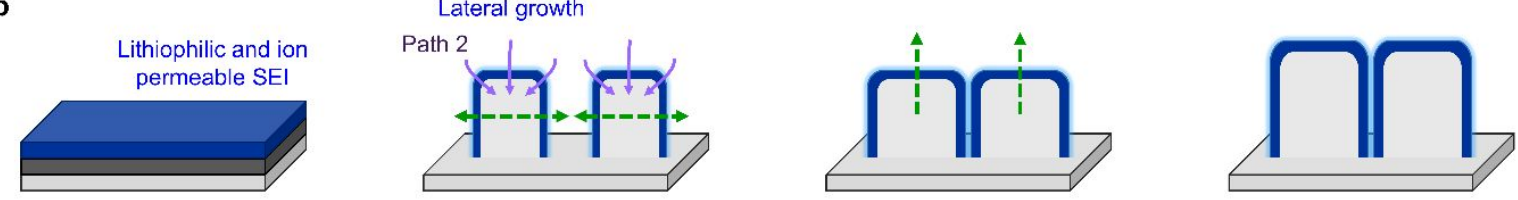

Figure S15. Schematic of Li plating process through (a) resistive and (b) lithiophilic and ionpermeable SEI layer on the Li metal anodes. 


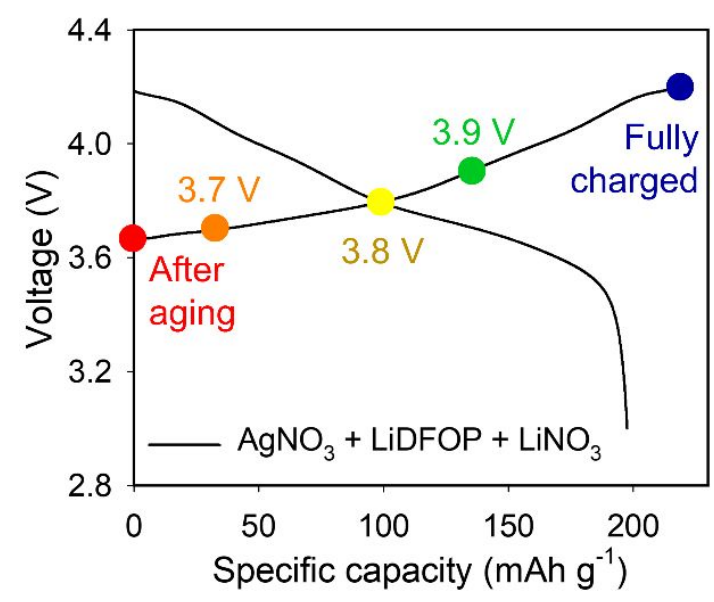

Figure S16. Voltage profile of $\mathrm{Li} \mid \mathrm{NCM} 84$ full cell precycled with $\mathrm{AgNO}_{3}+\mathrm{LiDFOP}+\mathrm{LiNO}_{3}$ at $\mathrm{C} / 10$ and $25^{\circ} \mathrm{C}$. The circles indicate the different voltages for XPS analysis at various state of charge (SOC) during precycling. 


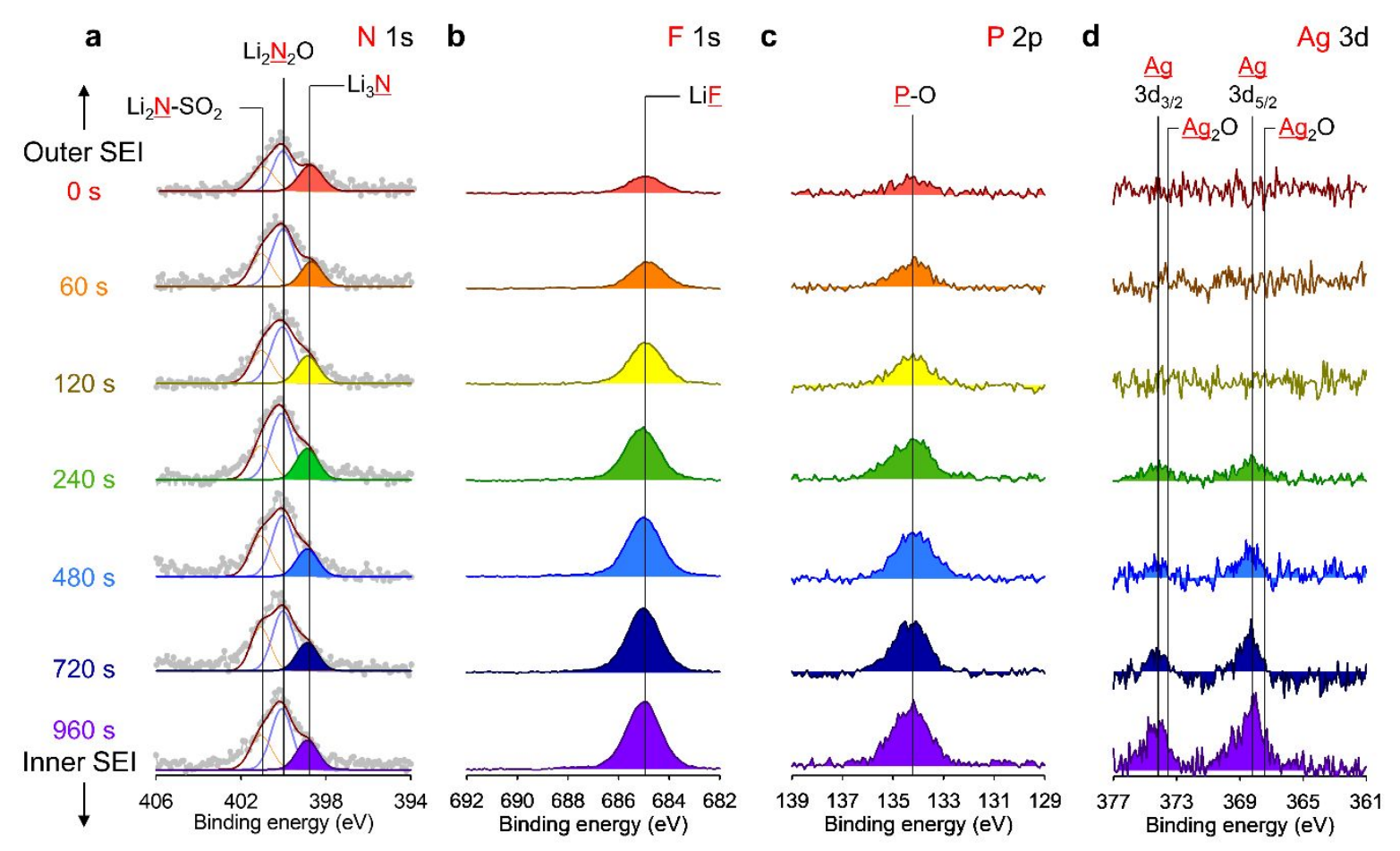

Figure S17. Surface chemistry of Li metal anodes retrieved from Li|NCM84 full cells cycled with $\mathrm{AgNO}_{3}+\mathrm{LiDFOP}+\mathrm{LiNO}_{3}$. XPS depth profiles of the (a) N 1s, (b) F 1s, (c) P 2p, and (d) Ag 3d spectra of the Li metal anodes obtained from the outer solid electrolyte interphase (SEI) (0 s, red) to the inner SEI (960 s, purple) layers after 30 cycles at $1 \mathrm{C}$ and $25^{\circ} \mathrm{C}$. 

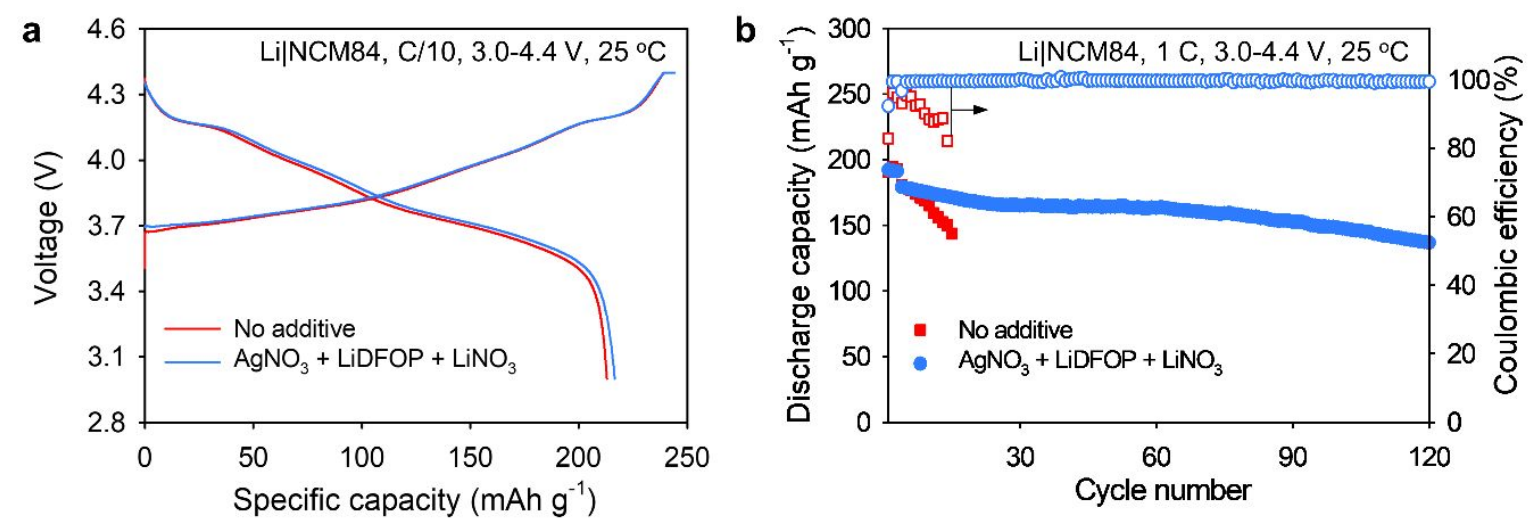

Figure S18. Electrochemical characteristics of Li|NCM84 full cells with and without $\mathrm{AgNO}_{3}$

$+\mathrm{LiDFOP}+\mathrm{LiNO}_{3}$. (a) Voltage profiles during precycling and (b) cycle performance of $\mathrm{Li} \mid \mathrm{NCM} 84$ full cells with and without $\mathrm{AgNO}_{3}+\mathrm{LiDFOP}+\mathrm{LiNO}_{3}$ over the potential range from 3.0 to $4.4 \mathrm{~V}$ after three standard cycles at $\mathrm{C} / 2$. The areal capacity of the NCM84 cathode was $2.65 \mathrm{mAh} \mathrm{cm}^{-2}$. 

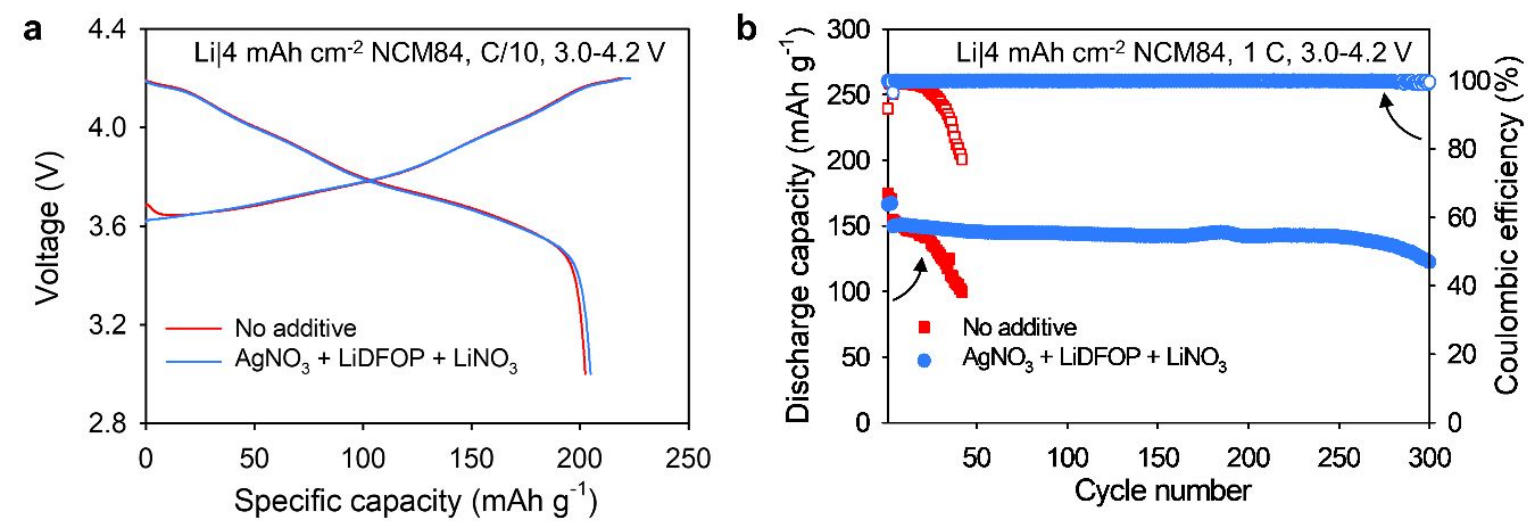

Figure S19. Electrochemical characteristics of Li|NCM84 full cells with and without $\mathrm{AgNO}_{3}$

$+\mathrm{LiDFOP}+\mathrm{LiNO}_{3}$. (a) Voltage profiles during precycling and (b) cycle performance of $\mathrm{Li} \mid \mathrm{NCM} 84$ full cells with and without $\mathrm{AgNO}_{3}+\mathrm{LiDFOP}+\mathrm{LiNO}_{3}$. Areal capacity of the NCM84 cathode was $4 \mathrm{mAh} \mathrm{cm}^{-2}$. 

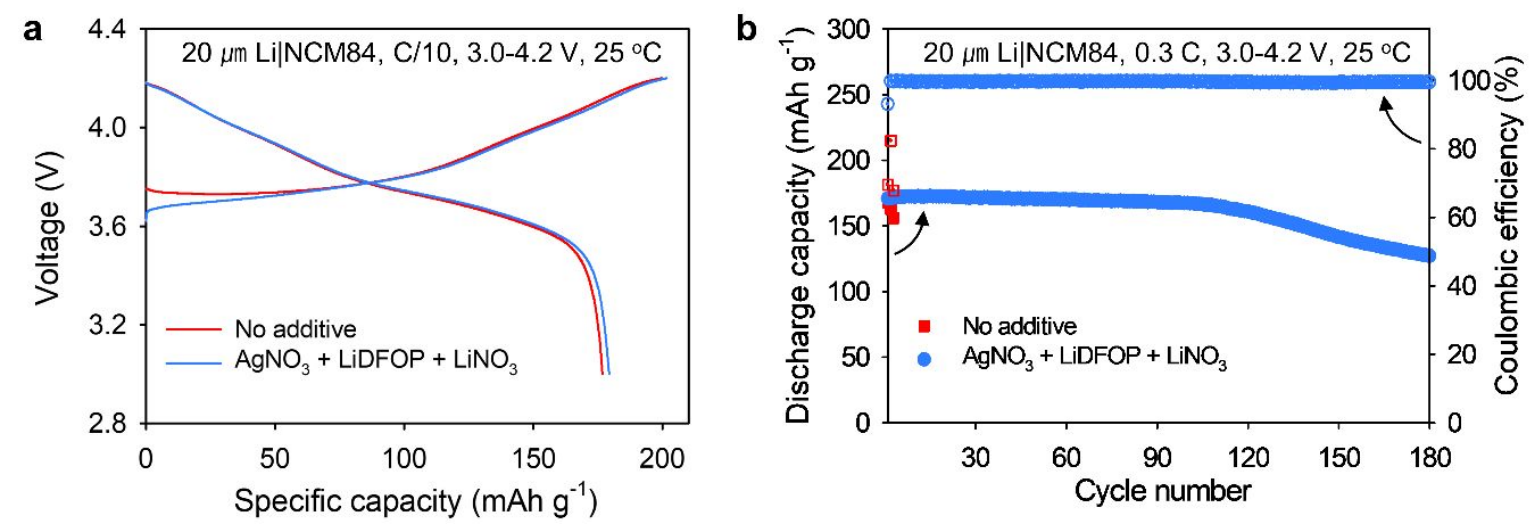

Figure S20. Electrochemical characteristics of Li|NCM84 full cells with and without $\mathrm{AgNO}_{3}$

$+\mathrm{LiDFOP}+\mathrm{LiNO}_{3}$. (a) Voltage profiles during precycling and (b) cycle performance of $\mathrm{Li} \mid \mathrm{NCM} 84$ full cells with and without $\mathrm{AgNO}_{3}+\mathrm{LiDFOP}+\mathrm{LiNO}_{3}$. The thickness of the $\mathrm{Li}$ metal was $20 \mu \mathrm{m}$ and the areal capacity of the NCM84 cathode was $2.65 \mathrm{mAh} \mathrm{cm}^{-2}$. 


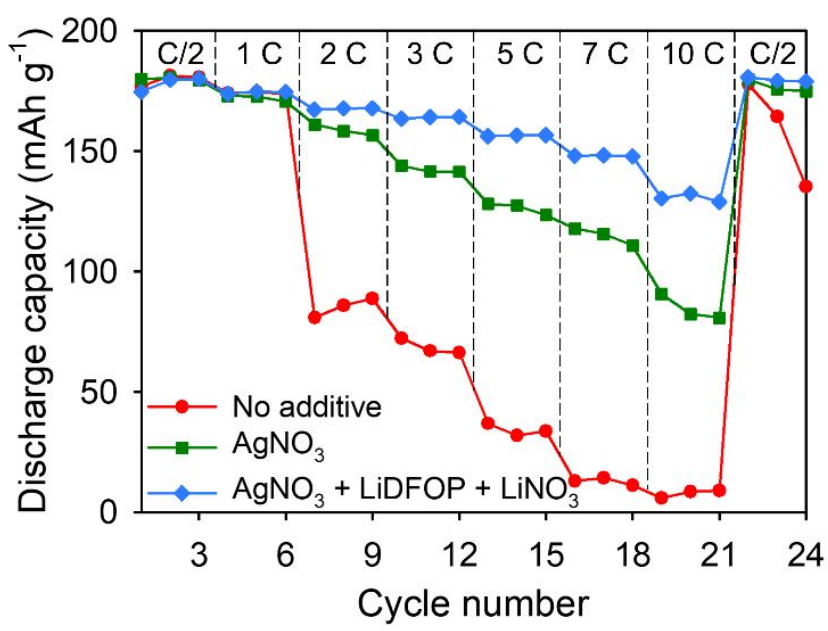

Figure S21. Discharge rate capability of $40 \mu \mathrm{m} \mathrm{Li} \mid \mathrm{NCM} 84$ full cells with no additive, $\mathrm{AgNO}_{3}$, and $\mathrm{AgNO}_{3}+\mathrm{LiDFOP}+\mathrm{LiNO}_{3}$ 


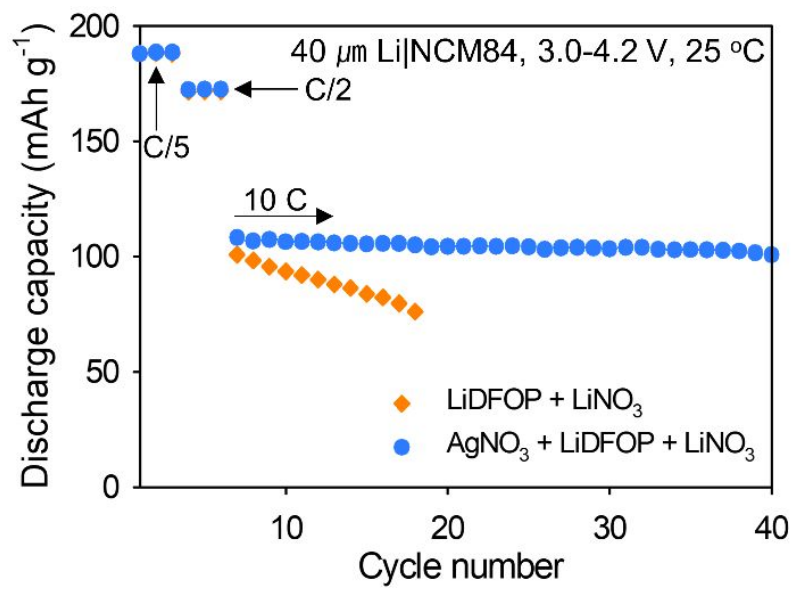

Figure S22. Cycling performance of $\mathrm{Li} \mid \mathrm{NCM} 84$ full cells with $\mathrm{LiDFOP}+\mathrm{LiNO}_{3}$ and $\mathrm{AgNO}_{3}$ $+\mathrm{LiDFOP}+\mathrm{LiNO}_{3}$ at a high discharge rate of $10 \mathrm{C}$ and $25^{\circ} \mathrm{C}$. 


\section{REFERENCES}

(1) Becke, A. D. Density-functional thermochemistry. III. The role of exact exchange. J. Chem. Phys. 1993, 98, 5648-5652.

(2) Stephens, P. J.; Devlin, F. J.; Chabalowski, C. F.; Frisch, M. J. Ab initio calculation of vibrational absorption and circular dichroism spectra using density functional force fields. $J$. Phys. Chem. 1994, 98, 11623-11627.

(3) Perdew, J. P.; Burke, K.; Ernzerhof, M. Generalized Gradient Approximation Made Simple. Phys. Rev. Lett. 1996, 77, 3865-3868.

(4) Brennan, M. D.; Breedon M.; Best A. S.; Morishita, T.; Spencer, M. J. S. Surface Reactions of Ethylene Carbonate and Propylene Carbonate on the Li(001) Surface. Electrochim. Acta 2017, 243, 320-330.

(5) Monkhorst, H. J.; Pack, J. D. Special points for Brillouin-zone integrations. Phys. Rev. B 1976, 13, 5188-5192.

(6) Delley, B. An all-electron numerical method for solving the local density functional for polyatomic molecules. J. Chem. Phys. 1990, 92, 508-517.

(7) Delley, B. From molecules to solids with the $\mathrm{DMol}^{3}$ approach. J. Chem. Phys. 2000, 113, $7756-7764$.

(8) Tkatchenko, A.; Scheffler, M. Accurate molecular van der waals interactions from groundstate electron density and free-atom reference data. Phys. Rev. Lett. 2009, 102, 073005.

(9) Mulliken, R. S. Electronic population analysis on LCAO-MO molecular wave functions. I. J. Chem. Phys. 1955, 23, 1833-1840.

(10) Mulliken, R. S. Electronic population analysis on LCAO-MO molecular wave functions. II. Overlap populations, bond orders, and covalent bond energies. J. Chem. Phys. 1955, 23, 1841-1846. 
(11) Klamt, A.; Schüürmann, G. COSMO: a new approach to dielectric screening in solvents with explicit expressions for the screening energy and its gradient. J. Chem. Soc. Perkin Trans. 1993, 2, 799-805.

(12) Hall, D. S.; Self, J.; Dahn, J. R. Dielectric constants for quantum chemistry and li-ion batteries: solvent blends of ethylene carbonate and ethyl methyl carbonate. J. Phys. Chem. C 2015, 119, 22322-22330. 